\title{
A comparative study of the effects of Aducanumab and scanning ultrasound on amyloid plaques and behavior in the APP23 mouse model of Alzheimer disease
}

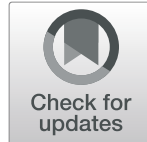

Gerhard Leinenga, Wee Kiat Koh and Jürgen Götz

\begin{abstract}
Background: Aducanumab is an anti-amyloid- $\beta$ (A $\beta$ ) antibody that achieved reduced amyloid pathology in Alzheimer's disease (AD) trials; however, it is controversial whether it also improved cognition, which has been suggested would require a sufficiently high cumulative dose of the antibody in the brain. Therapeutic ultrasound, in contrast, has only begun to be investigated in human AD clinical trials. We have previously shown that scanning ultrasound in combination with intravenously injected microbubbles (SUS), which temporarily and safely opens the blood-brain barrier (BBB), removes amyloid and restores cognition in APP23 mice. However, there has been no direct testing of how the effects of SUS compare to immunotherapy or whether a combination therapy is more effective.

Methods: In a study comprising four treatment arms, we tested the efficacy of an Aducanumab analog, Adu, both in comparison to SUS, and as a combination therapy, in APP23 mice (aged 13-22 months), using sham as a control. The active place avoidance (APA) test was used to test spatial memory, and histology and ELISA were used to measure amyloid. Brain antibody levels were also determined.

Results: We found that both Adu and SUS reduced the total plaque area in the hippocampus with no additive effect observed with the combination treatment (SUS + Adu). Whereas in the cortex where there was a trend towards reducing the total plaque area from either Adu or SUS, only the combination treatment yielded a statistically significant decrease in total plaque area compared to sham. Only the SUS and SUS + Adu groups included animals that had their plaque load reduced to below $1 \%$ from above $10 \%$. There was a robust improvement in spatial memory for the SUS + Adu group only, and in this group the level of Adu, when measured 3 days post-treatment, was 5 -fold higher compared to those mice that received Adu on its own.

Together, these findings suggest that SUS should be considered as a treatment option for AD. Alternatively, a combination trial using Aducanumab together with ultrasound to increase brain levels of the antibody may be warranted.
\end{abstract}

Keywords: Alzheimer's disease, Blood-brain barrier, Dementia, Amyloid- $\beta$, Immunotherapy, Focused ultrasound

\footnotetext{
* Correspondence: j.goetz@uq.edu.au

Clem Jones Centre for Ageing Dementia Research, Queensland Brain

Institute, The University of Queensland, Brisbane, QLD 4072, Australia
}

(c) The Author(s). 2021 Open Access This article is licensed under a Creative Commons Attribution 4.0 International License, which permits use, sharing, adaptation, distribution and reproduction in any medium or format, as long as you give appropriate credit to the original author(s) and the source, provide a link to the Creative Commons licence, and indicate if changes were made. The images or other third party material in this article are included in the article's Creative Commons licence, unless indicated otherwise in a credit line to the material. If material is not included in the article's Creative Commons licence and your intended use is not permitted by statutory regulation or exceeds the permitted use, you will need to obtain permission directly from the copyright holder. To view a copy of this licence, visit http://creativecommons.org/licenses/by/4.0/ The Creative Commons Public Domain Dedication waiver (http://creativecommons.org/publicdomain/zero/1.0/) applies to the data made available in this article, unless otherwise stated in a credit line to the data. 


\section{Background}

The deposition of amyloid- $\beta(\mathrm{A} \beta)$ in the brain is considered to be a key initiating step in the development of Alzheimer's disease (AD). Approaches that either prevent or remove the accumulation of $A \beta$ in the brain have been a focus of research into developing a therapy for this disorder [1-3], with several active and passive immunization strategies being explored in clinical trials to enhance $A \beta$ clearance from the brain.

Aducanumab is an anti- $A \beta$ antibody that targets $A \beta$ aggregates including insoluble fibrils and soluble oligomers, by binding to the amino-terminus of $A \beta$ at residues 3-7 in a shallow pocket in the antibody [4]. This human IgG1 antibody was isolated from the B cells of cognitively healthy elderly humans and has low affinity for monomeric $A \beta$ [5]. In a Biogen-sponsored phase Ib clinical trial (PRIME) of Aducanumab in prodromal and mild AD patients, a striking reduction in amyloid plaques as measured by positron emission tomography (PET) was reported following one year of monthly intravenous antibody infusions at doses ranging from 3 to $10 \mathrm{mg} / \mathrm{kg}$. One of the two phase III trials of Aducanumab, EMERGE, unlike ENGAGE, showed reductions in cognitive decline, possibly reflecting the effects of higher accumulated doses of the antibody [6]. Biogen is currently seeking U.S. Food and Drug Administration (FDA) approval for Aducanumab and may be granted conditional approval of the therapy pending a post-market commitment of a phase IIIB re-dosing trial that has recently been launched. If approved, it will be the first anti-amyloid agent and first antibody treatment for AD. However, it remains to be determined whether Aducanumab is a disease-modifying therapy that achieves significant clinical benefits in AD patients [7]. The interpretation of the cognitive data from these trials is complex, given that dosing was altered or stopped during the trial, and the magnitude of the cognitive effect was relatively small. Sevigny et al [5] demonstrated 50\% plaque reduction in 9.515.5-month-old amyloid precursor protein (APP) mutant Tg2576 mice after treating with a mouse IgG2a Aducanumab analog; however, the effects of the immunotherapy on behavioral read-outs in mouse models have not been reported.

Therapeutic ultrasound is an alternative strategy for clearing amyloid by transiently opening the blood-brain barrier (BBB) and allowing for the uptake of bloodborne factors and therapeutic agents [8]. Given that ultrasound parameters are highly tunable, this technique can be safely applied to a range of species, including mice [9, 10], dogs [11], sheep [12, 13], and macaques $[14,15]$ as well as humans [16]. Even without using a therapeutic agent (such as an antibody), repeated opening of the BBB with the scanning ultrasound (SUS) approach in 12 and 22 month-old APP23 mice has been shown to activate microglia, thereby reducing amyloid and improving memory performance $[17,18]$. This was shown to be dependent on $\mathrm{BBB}$ opening rather than simply applying ultrasound without microbubbles to induce a neuromodulatory effect [19]. The underlying mechanisms of ultrasound-mediated BBB opening have not been fully dissected but involve both facilitated para- and transcellular transport [20]. In preclinical studies, ultrasound has also been used to deliver model molecules of various sizes [21], as well as antibodies [22-24] to the brain.

Here, we sought to compare the efficacy of treatment with an Aducanumab analog (Adu) alone, SUS alone, and a combination of both SUS and Adu in terms of plaque reduction and performance in a spatial memory task.

\section{Materials and methods Study design}

APP23 mice express human APP751 with the Swedish double mutation (KM670/671NL) under the control of the neuron-specific mThy1.2 promoter. As they age, these mice exhibit memory deficits [25], amyloid plaque formation which is initiated in the cortex, and cerebral amyloid angiopathy (CAA) [26]. In this study, APP23 mice, aged 13 months, were assigned to four treatment groups: sham $(N=10)$, SUS $(N=11)$, Adu $(5 \mathrm{mg} / \mathrm{kg}$ delivered retroorbitally, $N=11)$, or SUS + Adu $(5 \mathrm{mg} / \mathrm{kg}$ retroorbitally, $N=10$ ). Assignment to treatment groups was based on matching performance of spatial memory (number of shocks) on day 5 of the active place avoidance (APA) test. We have previously shown that this approach reduces variability because mice yield similar results when repeatedly tested (as revealed by a main effect of subject) [17], and repeated APA testing of the same mouse can detect the effect of hippocampal injury and exercise, demonstrating the intra-animal validity of this approach [27]. A group of wild-type mice $(N=12)$ was also included. APP23 mice were ranked from those receiving the fewest shocks to those receiving the most shocks on day 5 and were assigned to the four treatment groups (sham, SUS, Adu, SUS + Adu) in rank order. Each group received a total of nine treatments (an APA retest was performed after the fourth treatment), with the final treatment in the Adu and SUS + Adu groups using fluorescently labeled antibody $(2.5 \mathrm{mg} / \mathrm{kg}$ Alexa Fluor 647-labeled Adu and $2.5 \mathrm{mg} / \mathrm{kg}$ unlabeled Adu) (Fig. 1a). Three days after the final treatment, the mice were administered an overdose of sodium pentobarbitone and perfused with phosphate-buffered saline (PBS). The right hemisphere of the brain was fixed in $4 \%$ paraformaldehyde for histology, while the cortex and hippocampus of the left hemisphere were dissected and frozen 


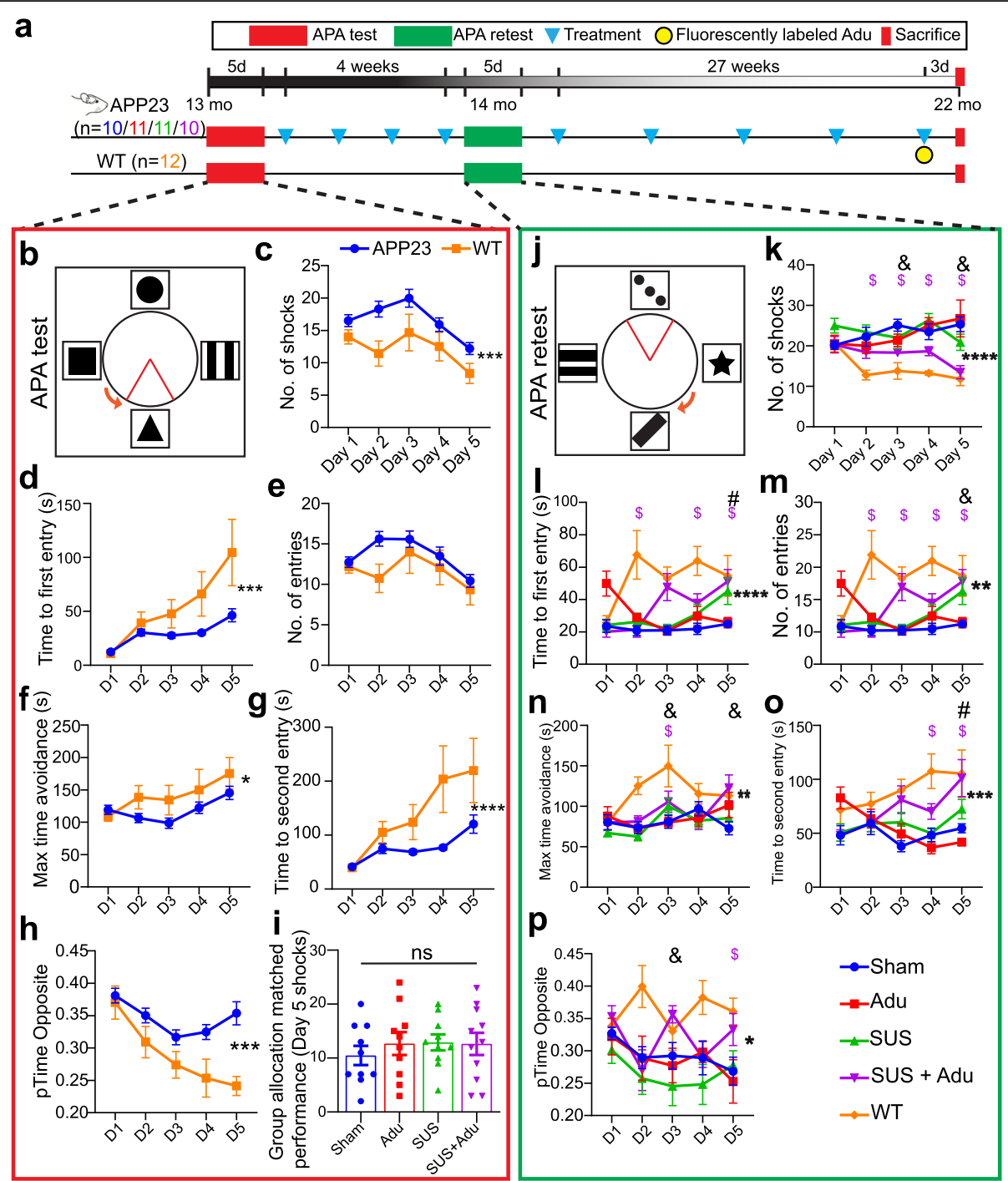

Fig. 1 Study overview and results of APA test and retest. Overview of the study with timeline (a). In the active place avoidance test (APA) mice must use spatial cues to avoid a shock zone (indicated as a red triangle) (b). APP23 mice had impaired performance in the APA test in terms of number of shocks received (c), and time to first entry to the shock zone (d) as determined by a two-way ANOVA. Although the APP23 mice did not show significant impairment in the measure number of entries (e) or maximum time avoidance (of the shock zone) (f), they were impaired on the measures time to second entry $(\mathbf{g})$ and proportion of time spent in the opposite quadrant to the shock zone (h). The mice were then assigned to treatment groups based on matching performance on day 5 of the APA test (i). The APA retest was performed after four once-perweek treatments with changes to room cues, shock zone location, and the direction of rotation (j). In the post-treatment APA retest an effect of SUS + Adu treatment on number of shocks compared to sham-treated mice was revealed (k), whereas treatment with SUS improved time to first entry (I). SUS + Adu improved the performance of the mice on the measures number of entries ( $\mathbf{m})$, and maximum time avoidance (n). Time to second entry was improved by SUS (o), while SUS + Adu improved the proportion of time spent in the opposite quadrant to the shock zone (p). Data are represented as mean \pm SEM. Statistical differences: ${ }^{*} p<0.05,{ }^{* *} p<0.01,{ }^{* * *} p<0.001,{ }^{* * * *} p<0.0001, \$=$ simple effect comparing wild-type vs sham $p<0.05$, \# = simple effect comparing SUS vs sham $p<0.05, \&=$ simple effect comparing SUS + Adu vs sham $p<0.05$. Sham $N=10$, Adu $N=11$, SUS $N=11$, SUS + Adu $N=10, W T N=12$. Data were analyzed with a two-way ANOVA and follow-up Holm-Sidak tests for simple effects

in liquid nitrogen for subsequent analysis. Due to the increased mortality of this strain [28], the numbers of mice surviving to 22 months for histological and biochemical analysis were $N=10$ sham, $N=9 \mathrm{Adu}, N=8$ SUS, and $N=9$ SUS + Adu. Assessment of outcomes was performed with the researcher blinded to the treatment group. All animal experimentation was approved by the
Animal Ethics Committee of the University of Queensland (approval number QBI/554/17). Sample sizes for the experiment were selected based on our earlier studies [17]. Due to availability, mostly male mice were used (males/females: $\operatorname{sham}=9 / 1$, Adu $=8 / 1$, SUS 7/1, SUS + Adu 7/2, Wild-type $=9 / 3$ in the mice that survived to 22 months). We were unable to perform a third APA test as 22-month 
old APP23 mice are unable to physically perform the task. Data was collected for all mice that survived until the end of the experiment and all data was included.

\section{SUS equipment}

An integrated focused ultrasound system (Therapy Imaging Probe System, TIPS, Philips Research) was used. This system consisted of an annular array transducer with a natural focus of $80 \mathrm{~mm}$, a radius of curvature of $80 \mathrm{~mm}$, a spherical shell of $80 \mathrm{~mm}$ with a central opening of $31 \mathrm{~mm}$ diameter, a 3D positioning system, and a programmable motorized system to move the ultrasound focus in the $\mathrm{x}$ and $\mathrm{y}$ planes to cover the entire brain area [17]. A coupler mounted to the transducer was filled with degassed water and placed on the head of the mouse with ultrasound gel for coupling, to ensure unobstructed propagation of the ultrasound to the brain.

\section{Production of microbubbles}

Microbubbles comprising a phospholipid shell and octafluoropropane gas core were prepared in-house. 1,2distearoyl-sn-glycero-3-phosphocholine (DSPC) and 1,2distearoyl-sn-glycero-3-phosphoethanolamine- $\mathrm{N}$-[amino (polyethylene glycol)-2000] (DSPE-PEG2000) (Avanti Polar Lipids) were mixed in a 9:1 $\mathrm{M}$ ratio and dissolved in chloroform (Sigma), after which the chloroform solvent was evaporated under vacuum. The dried phospholipid cake was then dissolved in PBS with $10 \%$ glycerol to a concentration of $1 \mathrm{mg}$ lipid/ml and heated to $55^{\circ} \mathrm{C}$ in a sonicating water bath. The solution was placed in a $1.5 \mathrm{ml}$ glass HPLC vial with the air in the vial replaced with octafluoropropane gas (Arcadophta). The microbubbles were activated on the day of the experiment by agitation of the vial in a dental amalgamator at $4000 \mathrm{rpm}$ for $45 \mathrm{~s}$. Activated microbubbles were measured with a Multisizer $4 \mathrm{e}$ coulter counter which reported a mean diameter of $1.885 \mu \mathrm{m}$ and a concentration of $9.12 \times 10^{8}$ microbubbles $/ \mathrm{ml}$. These microbubbles were also observed to be polydisperse under a microscope (Supplementary Figure 1).

\section{SUS application}

Mice were anesthetized with ketamine $(90 \mathrm{mg} / \mathrm{kg})$ and xylazine $(6 \mathrm{mg} / \mathrm{kg})$, and the hair on their head was shaved and depilated. They were then injected retroorbitally with $1 \mu \mathrm{l} / \mathrm{g}$ body weight of microbubble solution and placed under the ultrasound transducer with the head immobilized. A heating pad was used to maintain normal body temperature. Parameters for the ultrasound delivery were $1 \mathrm{MHz}$ center frequency, $0.7 \mathrm{MPa}$ peak rarefactional pressure, $10 \mathrm{~Hz}$ pulse repetition frequency, $10 \%$ duty cycle, and a 6 -s sonication time per spot. The focus of the transducer was $1.5 \mathrm{~mm} \times 12 \mathrm{~mm}$ in the transverse and axial planes, respectively. The motorized positioning system moved the focus of the transducer array in a grid with $1.5 \mathrm{~mm}$ spacing between individual sites of sonication so that ultrasound was delivered sequentially to the entire brain as described previously $[17,18]$. Mice typically received a total of 24 spots of sonication in a $6 \times 4$ raster grid pattern. For the sham treatment, mice received all injections and were placed under the ultrasound transducer, but no ultrasound was emitted. When the animals were treated with Adu antibody, the solution was mixed briefly with the microbubble solution and injected into the retro-orbital sinus before the mouse was placed under the ultrasound transducer. The time between injecting microbubbles and commencing ultrasound delivery was $60 \pm 10 \mathrm{~s}$ and the duration of sonication was approximately $3 \mathrm{~min}$ (total time from microbubble injection approximately $4 \mathrm{~min}$ ). We assumed that $100 \%$ of the antibody reached the circulation where it circulated with a half-life of 2.5 days [5] and that there was no interference from mixing with the microbubbles which have a half-life of 2 min.

\section{Production of the Aducanumab analog}

$\mathrm{VH}$ and VL sequences were identified in Biogen Idec's patent submission for BIIB-037 WO2014089500 A1 and were cloned into mouse IgG2a and kappa pcDNA3.1 vectors (GenScript). Murine chimeric Aducanumab (Adu) was produced using the Expi293 expression system, purified using protein A chromatography and verified to be endotoxin-free by LAL assay (Thermo Fisher).

\section{Antibody affinity ELISA}

The $\mathrm{EC}_{50}$ of Adu was determined by direct-binding ELISA. $\mathrm{A} \beta_{1-42}$ fibrils were generated by incubating 0.1 $\mathrm{mM} \mathrm{A} \beta_{1-42}$ peptide (JPT Peptide Technologies) in 10 $\mathrm{mM} \mathrm{HCl}$ for $3 \mathrm{~d}$ at $37^{\circ} \mathrm{C}$. A MaxiSorp ELISA plate was coated with $2 \mu / \mathrm{ml} \mathrm{A} \beta_{1-42}$ fibrils in $0.1 \mathrm{M}$ sodium bicarbonate buffer and then blocked with $1 \%$ bovine serum albumin. The $\mathrm{EC}_{50}$ was determined by incubating the wells with serial dilutions of Adu, followed by washing and detection of bound Adu with a rabbit anti-mouse horseradish-peroxidase-conjugated antibody (Dako) and 3,3',5,5' -tetramethylbenzidine substrate. The $6 \mathrm{E} 10$ antibody [29] was used as a positive control for $\mathrm{A} \beta$ binding and its $\mathrm{EC}_{50}$ was determined for comparison with Adu using the same methods (Supplementary Figure 2).

\section{Antibody labeling}

Adu was covalently conjugated with Alexa Fluor 647 dye (Thermo Fisher Scientific) in PBS with $0.1 \mathrm{M}$ sodium bicarbonate as previously described [22]. The protein concentration and degree of labeling were determined by measuring absorbance at $280 \mathrm{~nm}$ and $650 \mathrm{~nm}$, respectively. 


\section{Tissue processing}

Mice were deeply anesthetized with pentobarbitone before being perfused with $30 \mathrm{ml}$ of PBS, after which their brains were dissected. One hemisphere of the brain was fixed overnight in a solution of $4 \% \mathrm{wt} / \mathrm{vol}$ paraformaldehyde, and then cryoprotected in 30\% sucrose and sectioned coronally at $40 \mu \mathrm{m}$ thickness on a freezing-sliding microtome (SM2000R, Leica). A one-in-eight series of sections was stored in PBS containing $0.01 \%$ sodium azide at $4{ }^{\circ} \mathrm{C}$ for subsequent staining.

\section{Assessment of amyloid plaques}

For the assessment of amyloid plaque load, an entire one-in-eight series of coronal brain sections taken from the start of the anterior commissure to the ventral hippocampus of one hemisphere at $40 \mu \mathrm{m}$ thickness was stained using the Campbell-Switzer silver stain protocol that discriminates fibrillar from less aggregated amyloid as previously described [17]. Stained sections were mounted onto microscope slides and imaged with a $\times 10$ objective on a Metafer bright-field VSlide scanner (MetaSystems) using Zeiss Axio Imager Z2. Analysis of amyloid plaque load was performed on all stained sections using ImageJ. Separate regions of interest were drawn around the cortex and dorsal hippocampus. As both black and amber plaques are present in the sections representing different types of amyloid compactness, they were analyzed separately using a color deconvolution method and automated thresholding to distinguish the two types of amyloid plaques. For the analysis of black plaques, a color deconvolution vector was used followed by the MaxEntropy auto thresholding function in Image). As black plaques consist mainly of diffuse fibrils, no size filter was applied. To measure amber plaques, a second color deconvolution vector was used, followed by invert function and automated thresholding using the triangle method in ImageJ, fill-holes function, and a $60-\mu \mathrm{m}^{2}$ size filter was applied. Using this method, plaque number, total plaque area, average plaque size, and \% area covered by plaque were obtained for both the black and amber plaques and summed to give total plaque area for the cortex and hippocampus. We were unable to analyze the hippocampus of one mouse in the Adu-treated group because of folds in the tissue.

\section{Assessment of cerebral amyloid angiopathy}

To assess CAA, a one-in-eight series of Campbell-Switzer silver-stained sections was examined. Regions of interest were drawn manually around areas of CAA in the cortex, which were distinguished from plaques by having a rodlike structure indicative of blood vessels and a diameter greater than $15 \mu \mathrm{m}$. Meningeal CAA which has a ringshaped structure and occurred close to the edge of the section was also measured. The number of CAA deposits per section, the average size, and the \% area of the brain sections positive for CAA staining were determined.

\section{Assessment of cerebral microbleeds}

Prussian blue staining was performed using freshly prepared 5\% potassium ferrocyanide and 5\% hydrochloric acid (Sigma) for $30 \mathrm{~min}$. Cerebral microbleeds were identified at a $\times 20$ magnification as focal clusters of blue hemosiderin deposits which were smaller than $50 \mu \mathrm{m}$ wide and appeared to have a perivascular location. A randomly selected subset of 5 mice per treatment group were stained and 4 sections were analyzed from each mouse.

\section{Immunofluorescence labeling}

Coronal $40 \mu \mathrm{m}$ sections were co-stained with the 4G8 antibody against $A \beta$ (1:1000, Covance) and against Iba1 (1:1000 Wako), followed by goat anti-mouse and goat anti-rabbit Alexa Fluor-conjugated secondary antibodies (1:2000, Thermo Fisher). Alexa Fluor 647-conjugated Adu was detected in situ without additional amplification. Sections were cover-slipped and imaged with a fluorescence slide scanner (Metafer).

\section{Enzyme-linked immunosorbent assay for $A \beta$}

Frozen cortices were homogenized in 10 volumes of a solution containing $50 \mathrm{mM} \mathrm{NaCl}, 0.2 \%$ diethylamine (DEA) with complete protease inhibitors, and Dounce homogenized by passing through 19 and 27 gauge needles. The samples were then centrifuged at $21,000 \times g$ for $90 \mathrm{~min}$ at $4{ }^{\circ} \mathrm{C}$. The supernatant was retained as the DEA-extracted soluble $A \beta$ fraction. The remaining pellets were resuspended in 10 volumes of $5 \mathrm{M}$ guanidine $\mathrm{HCl}$, sonicated, and centrifuged at $21,000 \times g$ for $30 \mathrm{~min}$ at $4{ }^{\circ} \mathrm{C}$. The resultant supernatant was retained as the guanidine-extracted insoluble $A \beta$ fraction. The concentrations of $A \beta_{40}$ and $A \beta_{42}$ were determined in brain lysates using ELISA kits according to the manufacturer's instructions (human $A \beta_{40}$ and $A \beta_{42}$ brain ELISA, Merck).

\section{Active place avoidance test}

The active place avoidance (APA) task is a test of hippocampus-dependent spatial learning. We used a repeated APA paradigm, where mice were tested in the APA one time and the performance of each mouse was used to assign that mouse to one of four treatment groups. This was done by ranking all the mice based on their performance and assigning them to the four groups in order so that the APA performance of each treatment group was the same. Following this, mice received either sham, SUS, Adu, or SUS + Adu treatment and 3 days after the last treatment mice were retested in the APA to assess whether there was an improvement in APA performance due to the treatment the mouse had 
received. For each APA test, APP23 mice and nontransgenic littermate controls were tested over 6 days in a rotating elevated arena (Bio-Signal group) that had a grid floor and a 32-cm-high clear plastic circular fence enclosing a total diameter of $77 \mathrm{~cm}$. High-contrast visual cues were present on the walls of the testing room. The arena and floor were rotated at a speed of $0.75 \mathrm{rpm}$, with a mild shock $(500 \mathrm{~ms}, 60 \mathrm{~Hz}, 0.5 \mathrm{~mA})$ being delivered through the grid floor each time the animal entered a 60-degree shock zone, and then every $1500 \mathrm{~ms}$ until the animal left the shock zone. The shock zone was maintained at a constant position in relation to the room. Recorded tracks were analyzed with Track Analysis software (Bio-Signal group). A habituation session was performed $24 \mathrm{~h}$ before the first training session during which the animals were allowed to explore the rotating arena for $5 \mathrm{~min}$ without receiving any shocks. A total of five training sessions were held on consecutive days, one per day with a duration of $10 \mathrm{~min}$. After day 5 of the first APA (test), APP23 mice were divided into four groups with mice matched so that the performance (number of shocks) of the four groups of mice on day 5 of the task was the same, for the retest. Following four once-a-week SUS or Adu treatments, the mice underwent the APA test again (reversal learning). The retest was held in the same room as the initial test. However, the shock zone was switched to the opposite side of the arena, the visual cues were replaced with different ones, and the platform was rotated clockwise rather than counterclockwise. The number of shocks, numbers of entries to the shock zone, time to first entry, time to second entry, and proportion of time spent in the opposite quadrant of the shock zone for sham, SUS, Adu, and SUS + Adu-treated groups were compared over the days of testing.

\section{Statistical analysis}

Statistical analyses were conducted with Prism 8 software (GraphPad). Values were always reported as mean \pm SEM. One-way ANOVA followed by the Holm-Sidak multiple comparisons test, or $t$ test was used for all comparisons except APA analyses where two-way ANOVA with day as a repeated measures factor and group as a between subjects factor was performed, followed by the Holm-Sidak multiple comparisons test for simple effects to compare group performance on different days. The model assumption of equal variances was tested by Brown-Forsyth or Bartlett tests, and the assumption of normality was tested by KolmogorovSmirnov tests and by inspecting residuals with QQ plots. All observations were independent, with allocation to groups based on active place avoidance where mice were ranked on performance and assigned to one of the four groups (sham, SUS, Adu, SUS + Adu) in order of number of shocks on day 5 listed from most to least shocks.

\section{Results}

Generation of Aducanumab analog and application

The Aducanumab analog Adu was generated by grafting the VH and VL chains of Aducanumab onto a mouse IgG backbone and expressing this in Expi293 cells. We then established that the affinity of Adu to fibrillar $A \beta_{42}$ $\left(\mathrm{EC}_{50} 81.7 \mathrm{pM}\right)$ was similar to that published earlier for Aducanumab ( $\left.\mathrm{EC}_{50} 100 \mathrm{pM}\right)$ [5]. In comparison, the $6 \mathrm{E} 10$ antibody had an EC50 of $1.18 \mathrm{nM}$ for $\mathrm{A} \beta_{42}$ fibrils (Supplementary Figure 2). Next, 13-month-old APP23 mice were divided into four groups (sham/Adu/SUS/ SUS + Adu) based on matching performance on day 5 (final day) of the initial APA test. A dose of $5 \mathrm{mg} / \mathrm{kg}$ Adu was given for each treatment, except for the last treatment where a mixture of $2.5 \mathrm{mg} / \mathrm{kg}$ unlabeled Adu and $2.5 \mathrm{mg} / \mathrm{kg}$ Alexa Fluor 647-labeled Adu was administered. The mice were initially treated once a week for 4 weeks, after which they were re-tested in the APA. From 15 to 22 months of age, the mice were subsequently treated five times, and then sacrificed three days following the last treatment, resulting in a total of nine treatments (Fig. 1a).

\section{Aducanumab analog, when delivered by SUS, improves spatial memory performance}

In the current study, we compared the effect of delivering the murine chimeric IgG2a Aducanumab analog, Adu, with a SUS treatment, using plaque burden and behavior as the major read-outs. We also assessed a combination treatment (SUS + Adu). Additional comparisons were made by including sham-treated mice, as well as untreated wild-type littermate controls.

We first tested 13 month-old APP23 mice and their wild-type littermates in the APA test of hippocampusdependent spatial learning in which the animals must use visual cues to learn to avoid a shock zone located in a rotating arena (Fig. 1b). Spatial learning was not assessed in the alternative Morris water maze test because this test is stressful to mice, and aged mice are poor swimmers [30,31]. To determine the effect of each treatment protocol on spatial memory function, an APA test consisting of 5 training days with a single $10 \mathrm{~min}$ training session each day was performed following habituation to the arena in one $5 \mathrm{~min}$ session the day before the first training day. A two-way ANOVA based on the number of shocks that were received revealed a significant effect of day of testing, indicating that learning had occurred $\left(F_{4,208}\right)=5.728, p=0.0003$. There was also a significant effect of genotype, with APP23 mice receiving more shocks than their wild-type littermates $\left(F_{1,52}\right)=6.278, p=0.0154$ (Fig. 1c). Similarly, based on the measure of time to first entry of the shock zone, there was a significant effect of day, with mice showing longer latencies to the first entrance as the number of 
training days increased $\left(F_{4,208}\right)=7.586, p=0.0007$. Wildtype mice exhibited longer latencies to enter the shock zone over the days of testing and there was a significant effect of genotype on time to first entry $\left(F_{1.52}\right)=5.950$, $p=0.0182$ (Fig. 1d). Wild-type and APP23 mice did not differ; however, on number of entries (Fig. 1e) or maximum time of avoidance of the shock zone (Fig. 1f). APP23 mice performed significantly worse on the measures "time to second entry" (Fig. 1g) and "proportion of time spent in the quadrant opposite to the shocked quadrant" (Fig. 1h). The APA performance of the APP23 mice varied significantly so they were assigned to each of the four treatment groups based on matching performance in terms of the number of shocks received on day 5 of the APA to reduce any differences in performance between treatment groups to more readily detect any improvement (Fig. 1i).

Before retesting in the APA, mice were treated once a week for 4 weeks. For the retest, the shock zone was shifted by $180^{\circ}$, the cues in the room were changed, and the arena rotated in the opposite direction. To perform well in the retest, the mice needed to update their spatial learning in order to learn the new shock zone location (Fig. 1j). A two-way ANOVA with group as a betweensubjects factor and day as a repeated measures factor revealed a significant effect of treatment group on number of shocks received $\left(F_{4,47}=8.5, p<0.0001\right)$. Follow-up multiple comparisons tests showed that SUS + Adutreated mice received significantly fewer shocks than sham-treated control mice on days $3(p=0.0295)$ and 5 $(p=0.0005)$ (Fig. 1k). Comparison of the Adu-treated to the SUS + Adu-treated mice by two-way ANOVA revealed that the combination treatment resulted in significantly improved performance over Adu alone in terms of number of shocks received during the test $\left(F_{1,17}=6.23, p=0.0231\right)$. A two-way ANOVA revealed a significant main effect of group $\left(F_{4,47}=6.8, p=0.0002\right)$ on time to first entry into the shock zone, with a followup multiple comparisons test showing that SUS-treated mice had a longer latency to enter the shock zone on day 5 of the APA task $(p=0.024)$ (Fig. 1l). SUS + Adutreated mice performed significantly better than sham-treated mice on the measures number of entries (Fig. $1 \mathrm{~m}$ ), and maximum time of avoidance (Fig. 1n) SUS-treated mice showed improvement on the measure time to second entry (Fig. 10). SUS + Adu-treated mice showed improvement in the measure proportion of time spent in the quadrant opposite the shock zone (Fig. 1p). These results demonstrate that APP23 mice exhibit an improvement in spatial memory when treated with a combination of SUS and Adu, and on some measures SUS alone improved performance in the APA.

\section{Comparison of plaque reduction in the cortex for the different treatment groups}

Following APA testing to ascertain the effects of four once-per-week treatments on spatial memory performance, APP23 mice had five further treatment sessions between the age of 15 and 22 months in order to determine whether SUS, Adu alone, or the combination resulted in robust plaque removal, even at older ages when plaque burden is maximal as the animals were no longer able to physically perform the APA task. The mice were sacrificed at 22 months of age, 3 days after the last treatment, and one hemisphere was processed for histology to identify plaques. We performed Campbell-Switzer staining, which can differentiate diffuse and compact species of amyloid plaques in the brain and is not confounded by the binding of Adu to $A \beta$. This revealed a reduction in the total plaque area when comparing the treatment groups to sham controls (Fig. 2a). We calculated the percentage area occupied by plaque for two regions of interest, the cortex and the hippocampus, in 15-20 sections per mouse, assessing plaque burden in a one-in-eight series of sections along the rostral-caudal axis starting from the anterior commissure and ending at the ventral hippocampus. Analysis of cortical plaque burden in the different groups revealed an effect of treatment $\left(F_{3,31}=3.78, p=0.02\right)$. A follow-up Holm-Sidak test found that combined SUS + Adu treatment resulted in a statistically significant $52 \%$ plaque reduction in the cortex of these mice compared to sham $(p=$ $0.0066)$. At 22 months of age, APP23 mice have a severe plaque burden, with diffuse and compact plaques occupying $23 \%$ of the cortex in the shamtreated mice, compared to $16 \%$ of the cortex in mice administered Adu, $17 \%$ in mice administered SUS only, and $11 \%$ in mice which received SUS + Adu treatment (Fig. 2b). As an additional analysis, the SUS + Adu treatment was found to be superior to Adu alone in reducing plaque burden (one-tailed $t$ test, $p=0.029$ ). As the Campbell-Switzer silver stain differentiates diffuse plaques which stained black with a cotton wool appearance, from compact plaques which stain amber (Fig. 2a), we also analyzed these plaques separately using a color deconvolution method in ImageJ. The results of this analysis revealed that the reduction in total plaque area was largely driven by a reduction in the total area of black plaque which occupied $18.60 \%$ of the cortical area in sham-treated mice compared to $7.93 \%$ in the SUS + Adu-treated animals $(p=0.0119)$ (Fig. 2c). In contrast, we found no significant difference between the treatment groups based on the area, number, or size of amber plaques (Fig. 2d,e,i). 


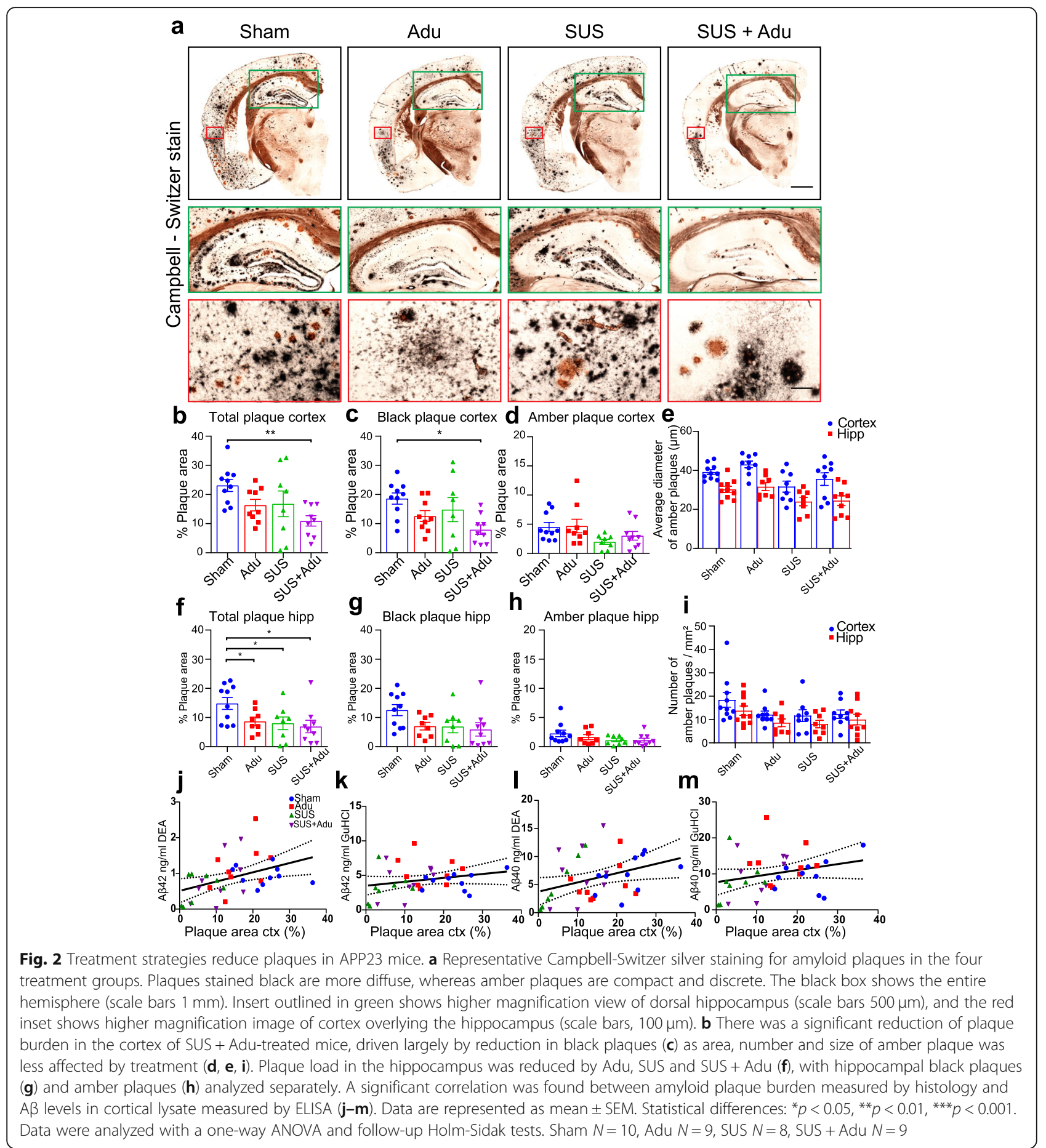

Aducanumab analog, SUS, and the combination therapy all effectively reduce amyloid plaques in the hippocampus of APP23 mice

In APP23 mice, plaque formation is initiated in the cortex and then proceeds to the hippocampus. When we analyzed the total plaque burden in the hippocampus, we found a significant effect of treatment $\left(\mathrm{F}_{3,31}=3.44\right.$, $p=0.03$, one-way ANOVA). All three treatments (Adu,
SUS and SUS + Adu) led to a significant reduction in total plaque area in the hippocampus compared to that in sham-treated APP23 mice (Fig. 2f). The sham-treated mice had a hippocampal plaque burden of $14.84 \%$ vs $8.68 \%$ for Adu-treated mice ( $p=0.0432)$, $8.04 \%$ for SUStreated mice $(p=0.043)$, and $6.92 \%$ for SUS + Adu-treated mice $(p=0.022)$. However, unlike the effects seen in the cortex, the reduction in total plaque in the hippocampus 
was not disproportionately driven by a reduction in black plaque $\left(F_{3,30}=2.43, p=0.08\right)$ (Fig. $\left.2 \mathrm{~g}\right)$ compared to amber plaque reduction $\left(F_{3,30}=1.80 p=0.17\right)$ (Fig. $\left.2 \mathrm{e}-\mathrm{i}\right)$, as it was only when total plaque burden was analyzed that statistically significant reductions were found. These results show that the effect of SUS on plaque burden in the hippocampus is comparable to that of Adu and the combination treatment provided no additive effect.

\section{Effects of treatment on amyloid- $\beta$ species}

We next performed ELISA measurements of A $\beta 40$ and $A \beta 42$ species from the lysate of one cortex, fractionating proteins into a DEA fraction containing soluble proteins and a guanidine fraction containing insoluble proteins. The levels of $A \beta 42$ and $A \beta 40$ in the DEA soluble fraction were significantly correlated to plaque burden as measured by Campbell-Switzer silver staining of the other hemisphere $\left(R^{2}=0.17, p=\right.$ 0.014 and $R^{2}=0.13, p=0.030$ respectively) (Fig. 2 j, l). The levels of $A \beta 42$ and $A \beta 40$ in the guanidine fraction containing insoluble $A \beta$ did not correlate significantly with plaque burden as measured by histology, most likely because most of the material stained by Campbell-Switzer silver staining is soluble in DEA (Fig. 2k, m).

\section{Aducanumab analog does not affect cerebral amyloid angiopathy in APP23 mice}

We also investigated whether there was any effect of treatment with SUS, Adu, or the combination of the two on CAA. APP23 mice exhibit amyloid deposition on the vasculature with advanced age [32]. We found that there was no effect of Adu or a combination of both on the number of blood vessels that were Campbell-Switzer positive and mice in all groups had significant deposition of amyloid on blood vessels (Fig. 3a). An average of twenty vessels were Campbell-Switzer positive per section, with an average of $0.75 \%$ of the total area of the cortex taken up by amyloid-laden blood vessels, and this did not differ between the groups (Fig. 3b).

\section{Aducanumab does not increase the number of microhemorrhages in APP23 mice}

We also investigated whether Adu or SUS + Adu treatment increased the occurrence of microhemorrhages as detected by Perl's Prussian blue staining for clusters of hemosiderin deposits (considered as a single microhemorrhage) and found that although microbleeds were common in APP23 mice, they did not increase in response to treatment $\left(F_{3,16}=0.94, p=0.44\right.$, one-way ANOVA) (Fig. 3b).

\section{SUS markedly increases the amount of the Aducanumab} analog in the brain

We also sought to determine the extent to which SUS was able to increase the amount of Adu in the brain. To investigate this we labeled Adu with Alexa Fluor 647 and injected the mice with $2.5 \mathrm{mg} / \mathrm{kg}$ of the fluorescently labeled Adu and $2.5 \mathrm{mg} / \mathrm{kg}$ unlabeled Adu at the last treatment session. In mice treated with Adu alone, fluorescently labeled Adu was faintly detectable by fluorescence microscopy and mainly confined to the outside edge of plaques (Fig. 4a). In contrast, in SUS + Adu mice, fluorescently labeled Adu decorated the entirety of plaques and was easily detectable (Fig. 4b). We also analyzed a subset of 5 mice per group to determine the area of the cortex that was positive for fluorescent Adu, revealing that $0.36 \%$ of the cortex in Adu-treated mice was positive compared to $1.59 \%$ in SUS + Adu mice $(p=$ $0.0096, t$ test). We also detected fluorescently-labeled Adu in mice injected with Adu and SUS + Adu in the cortical lysate and found that levels were $4.32 \mathrm{ng} / \mathrm{ml}$ on average in the Adu group compared to $21.77 \mathrm{ng} / \mathrm{ml}$ in the SUS + Adu-treated group ( $p=0.0175, t$ test) (Fig. $4 \mathrm{c}$ )

\section{Discussion}

Amyloid-targeted immunization strategies in AD have a long history, whereas therapeutic ultrasound has only recently been explored as a treatment modality. Our earlier studies and those of others have revealed that ultrasound in combination with microbubbles, but in the absence of a therapeutic agent, can clear protein aggregates such as the hallmark lesions of $\mathrm{AD}, \mathrm{A} \beta$ plaques $[17,18,33,34]$, and tau-containing neurofibrillary tangles $[20,22,35]$. We have also previously shown that the application of SUS achieves BBB opening throughout the brain [17] and, consequently, results in higher brain concentrations of antibodies in an IgG format, with a 19-fold higher concentration of IgG reaching the brain as compared to peripheral injection without SUS [23]. Studies by us in tau transgenic mice [22, 23] and work by others $[24,36]$ have suggested that ultrasound can also be used as an effective drug delivery tool to increase the level of antibodies in the AD brain.

Here, we used a multi-arm study, in which we compared the effects of SUS, the Aducanumab analog, Adu, delivered peripherally, and Adu delivered to the brain using SUS in APP23 mice with plaque pathology, using a sham treatment and wild-type mice as controls. In our study, SUS treatment had comparable effects to Adu treatment on plaque burden and behavior. We further found that in our treatment paradigm (nine treatments from age 13 to 22 months of age), Adu delivered across the BBB with SUS produced a more marked reduction in the amyloid plaque burden in the cortex of 22 monthold APP23 mice compared to the effects of either the 

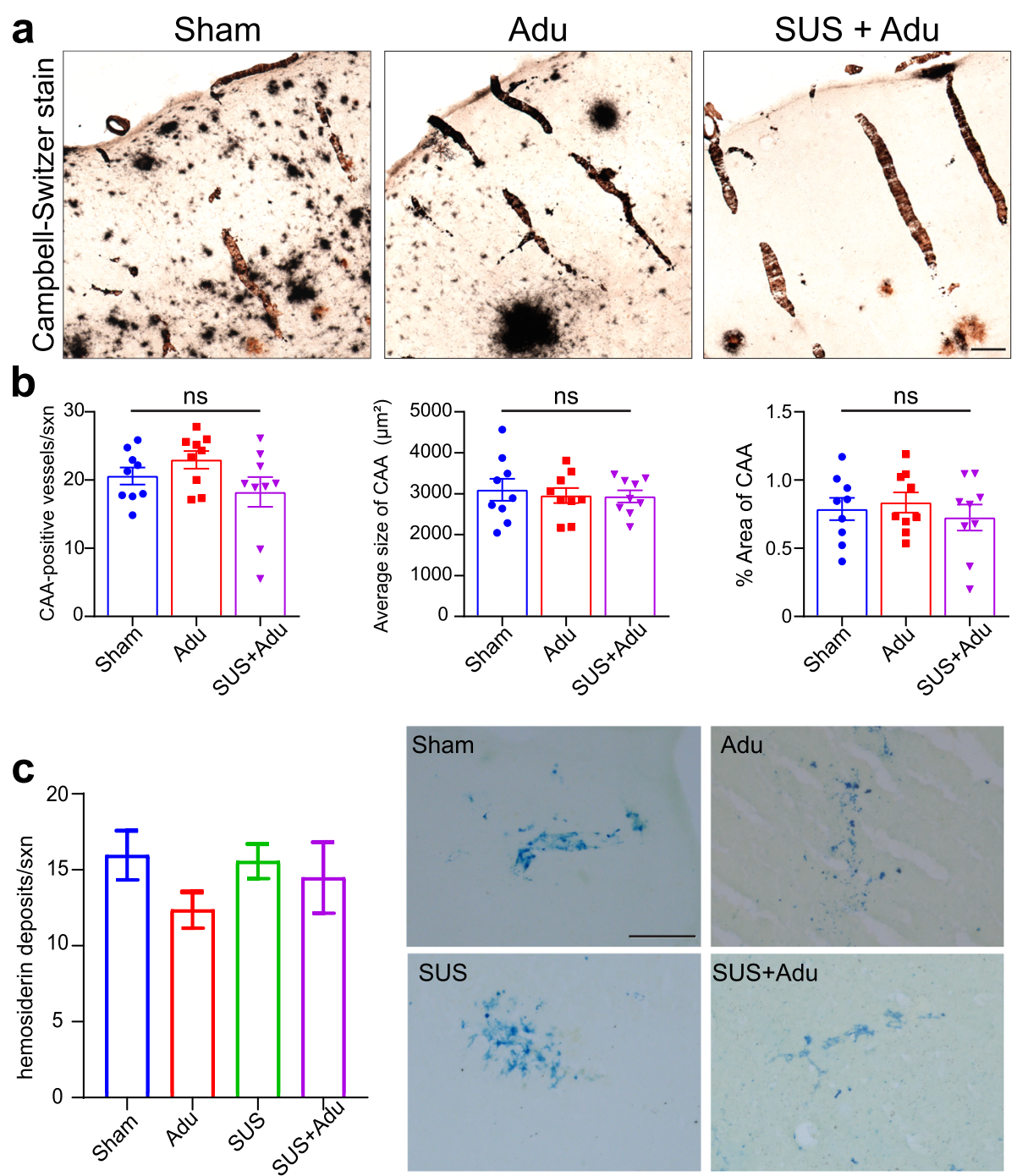

Fig. 3 Aducanumab analog does not affect levels of cerebral amyloid angiopathy (CAA) or microhemorrhages in APP23 mice. a Representative Campbell-Switzer silver staining shows CAA in the cortex identified by a rod-like appearance, as well as meningeal CAA identified as open circles on top of the cortex. $\mathbf{b}$ Adu, whether administered with or without SUS, had no effect on the number of CAA-affected vessels, average size, or percent area occupied by CAA. c Adu, whether administered by itself or with SUS, had no effect on the number of microhemorrhages detected by Prussian blue staining in 22-month old APP23 mice. Data are represented as mean \pm SEM. Statistical differences: ${ }^{*} p<0.05$. Data were analyzed with a one-way ANOVA and $t$ test. Scale bar $200 \mu \mathrm{m}$

antibody or SUS alone, concomitant with improvements in memory. For the first time, we report data on the effect of an Aducanumab analog in a spatial memory task in plaque-bearing $\mathrm{AD}$ model mice. We initially performed the APA test of spatial memory and learning in 13 month-old APP23 mice to obtain a baseline, and then divided the mice into treatment groups based on their performance, which we reasoned would allow us to achieve greater power to detect improvements caused by the treatment due to reduced variability between the groups. We treated mice weekly for 4 weeks and then repeated the APA test in which mice had to learn new spatial cues to avoid the shock zone. This experimental design allowed us to detect an improvement in mice treated with the combination of SUS + Adu compared to sham-treated mice and to detect improved performance in mice treated with the combination compared to mice treated with Adu alone.

We were also interested in the effect of treatment on amyloid plaque burden, specifically at an advanced age (22 months old) in mice when plaque burden is more similar to that of an early $\mathrm{AD}$ patient. Interestingly, plaque reduction in the hippocampus could be achieved with any of the three treatments (SUS, Adu and the combination), possibly reflecting the lower degree and 

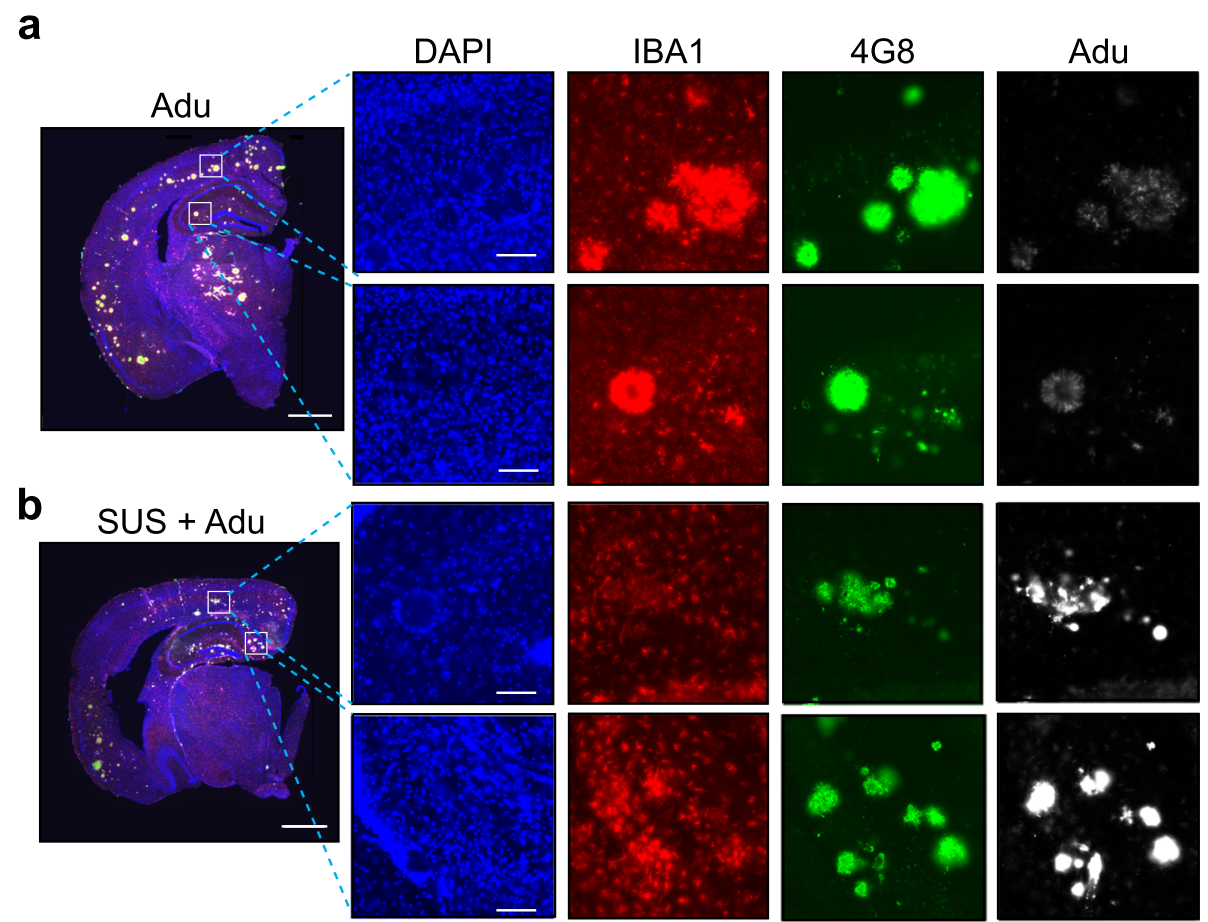

C

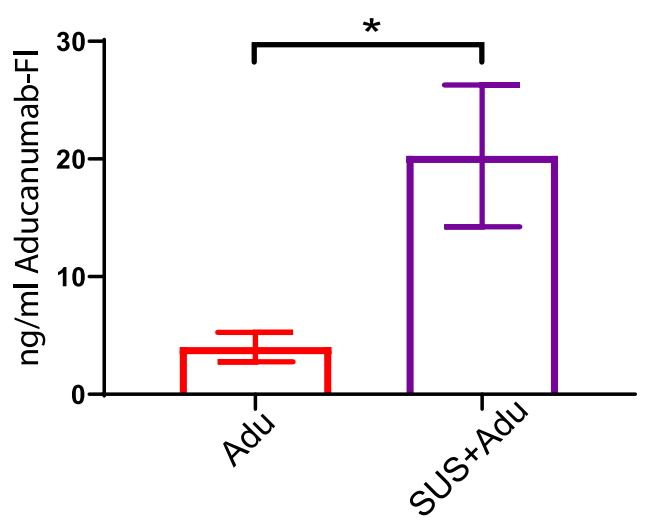

Fig. 4 Scanning ultrasound (SUS) increases the levels of the Aducanumab analog in the brain. a Fluorescently labeled Adu is detectable in the whole brain (scale bars $1 \mathrm{~mm}$ ) and when visualized at higher magnification in the cortex and hippocampus (scale bars $100 \mu \mathrm{m}$ ). In APP23 mice treated with Adu alone, the fluorescent Adu is bound to plaques, which were immunolabeled with 4G8 antibody. $\mathbf{b}$ The levels of Adu were higher when Adu was delivered together with SUS in SUS + Adu-treated mice. The amyloid plaques in SUS + Adu-treated mice were decorated all over with Adu, whereas in mice treated with Adu alone the Adu is mainly confined to the outsides of the plaques. Microglia as identified by IBA1 immunostaining were located near plaques which have Adu bound to them. $\mathbf{c}$ The levels of fluorescent antibody in the cortical brain lysate was greatly increased in the SUS + Adu group compared to the Adu group. Data are represented as mean \pm SEM. Statistical differences: ${ }^{*} p<0.05$. Data were analyzed with $t$ test. Adu $N=9$, SUS + Adu $N=9$

later appearance of pathology in this brain area. Somewhat surprisingly, we did not see an improvement in CAA; however, this is in line with findings by Sevigny et al. [5] and could be due to efflux of $A \beta_{40}$ and $A \beta_{42}$ leading to relocation of parenchymal plaques to the vasculature. In clinical trials, microbleeds detectable with MRI occurred in less than $10 \%$ of patients [5]; however, in this study, Aducanumab was not found to increase the occurrence of microbleeds in APP23 mice which could be due to the lower cumulative dose or differences between the parent antibody and the chimeric mouse IgG2a antibody, Adu, used in this study. Spatial memory was improved in 14-month-old APP23 mice following four weekly treatments with a combination of Adu and SUS. We have previously shown that a combination therapy using SUS and an anti-tau antibody in IgG format increased the uptake 19-fold when measured one hour after treatment [23]. In line with these findings, in this study we observed a fivefold increased levels of Adu in this study when administered in combination with SUS, which 
was measured at a three day time point. The total increased uptake would likely be higher if measured at earlier time points post-injection, as IgG is cleared from the CNS or taken up by microglia as time progresses.

Delivering higher amounts of an anti-A $\beta$ antibody into the brain should increase the efficacy of immunotherapy. This could in principle be achieved by strategies that bypass the BBB such as direct injection into the CNS. In one study, intracranial delivery of Aducanumab by topical application to the cortex was found to rapidly clear plaques in 22-month-old Tg2576 mice, whereas peripheral injections at $10 \mathrm{mg} / \mathrm{kg}$ repeated weekly from 18 to 24 months of age proved ineffective at clearing plaques, although they did restore physiological levels of intraneuronal calcium [37]. In contrast, plaque reduction was reported by Sevigny and colleagues when Aducanumab was delivered peripherally in Tg2576 mice. Weekly 10 $\mathrm{mg} / \mathrm{kg}$ injections begun at 9.5 months of age reduced plaque burden by $50 \%$ at 15.5 months, suggesting that Aducanumab treatment may be less effective at removing plaques in mice which already carry a substantial plaque burden compared to preventing plaque formation [5]. Our results show that administering a much lower cumulative dose of an Aducanumab analog than these authors used was ineffective at clearing plaques in the cortex of APP23 mice when treatment was commenced at 13 months of age; however, hippocampal plaques which develop at a more advanced age were reduced. Greater plaque reduction in the hippocampus could also be due to differences in the cerebral vasculature that result in greater drug delivery in the hippocampus than cortex [22]. In contrast to peripheral injections alone, delivery of the Adu using SUS led to a reduction in both cortical and hippocampal plaques, concomitant with increased brain levels of the antibody.

Efforts are currently underway in several laboratories to develop therapeutic ultrasound into a treatment modality for $\mathrm{AD}$ and other brain diseases, with ongoing clinical trials using an FDA-approved focused ultrasound system (ExAblate Neuro, Insightec) $[16,38]$ and implanted transducers [39] (Sonocloud, Carthera). These studies are applying ultrasound with microbubbles, but without a therapeutic agent such as an anti-A $\beta$ antibody, with safe and effective $\mathrm{BBB}$ opening being used as primary endpoints, and $A \beta$ clearance as a secondary endpoint. There are clearly several obstacles ahead such as being able to open a large enough brain area repeatedly and safely $[8,40]$. Use of therapeutic ultrasound to open the BBB offers the possibility of achieving better brain uptake of a drug that has shown evidence of clinical efficacy, such as Aducanumab [5]. There is also the possibility of reducing the level of antibody that needs to be administered to achieve the same therapeutic outcome, by using ultrasound. This study provides further evidence also for the use of ultrasound opening of the BBB without a therapeutic agent by showing it is not inferior to an anti-A $\beta$ immunotherapy and potentially works through the mechanism of increasing microglial phagocytosis of $A \beta[5,17]$. More importantly, we believe that ultrasound can be combined with therapeutic agents (such as an anti-tau antibody and an anti-A $\beta$ antibody) at levels below a safety threshold. What has not been discussed here is the potential of applying ultrasound to target the brain in either a global or a more focused manner. We anticipate that once therapeutic ultrasound has overcome the critical approval hurdles, it may develop into a highly versatile and effective treatment therapy not only for AD but also for other brain diseases.

\section{Limitations}

It must be acknowledged that the current study has some limitations. APP23 mice exhibit significant variability in plaque burden and behavior between animals. The strain is also characterized by a $>40 \%$ mortality which presented a challenge in obtaining the high numbers of mice required for the multiple treatment arms. We also used only one APP transgenic mouse strain, and this strain lacks a tau pathology which could limit the clinical relevance of our findings. In addition, most of the mice were male, as a result of which we cannot rule out the possibility that there could be differences in the efficacy of treatment in females and this deserves further study as sex differences in APP23 mice pathology have been reported [41]. Due to the advanced age of the mouse cohort at the end of the treatment period, memory function could not be assessed for a third time. Moreover, only one cognitive test was used to assess spatial memory. Several mice also died prematurely which was due to the premature lethality phenotype of APP23 mice, most likely due to excitotoxicity [28]. We did not observe any differences in deaths between groups, and the age at death did not differ between groups, appearing random. The nature of these deaths and the age at which the treatments were performed precluded detailed investigations of the lethality phenotype. In addition, we only tested one dose of Adu which at $5 \mathrm{mg} / \mathrm{kg}$ was lower than the maximum dose tested in the EMERGE and ENGAGE clinical trials of $10 \mathrm{mg} / \mathrm{kg}$.

\section{Conclusions}

An effective therapy for AD would reduce amyloid load and improve cognition. Here, we show that an Aducanumab analog, Adu or SUS alone have a comparable ability to reduce amyloid levels. The combination of SUS and Adu also improves cognitive function as measured by the APA test, suggesting that a trial using Aducanumab in combination with ultrasound to open the BBB has 
merit as this approach may lead to increased brain levels of Aducanumab. Our data add to the growing literature on applying therapeutic ultrasound either on its own or in combination to treat brain diseases such as AD.

\section{Abbreviations}

AD: Alzheimer's disease; SUS: Scanning ultrasound; A 3 : Amyloid beta; ELISA: Enzyme linked immunosorbent assay; Iba1: lonized calcium binding adaptor molecule 1; IgG: Immunoglobulin; Adu: Aducanumab mouse IgG2a chimeric analogue; Tg: Transgenic; WT: Wild-type

\section{Supplementary Information}

The online version contains supplementary material available at https://doi. org/10.1186/s13195-021-00809-4

\section{Additional file 1: Supplementary Figure 1. Characterization of} microbubbles. (a) In-house prepared microbubbles were analyzed by Coulter Counter and number of microbubbles per $\mathrm{ml}$ with size displayed. (b) Microbubbles were observed under a microscope at 20x magnification. Scale bar $10 \mu \mathrm{m}$.

Additional file 2: Supplementary Figure 2. Affinity measurement of Aducanuman analog, $A d u$. The affinity of Adu for fibrillar $A \beta_{42}$ was determined by ELISA and compared to the antibody $6 \mathrm{E} 10$.

\section{Acknowledgements}

We thank Linda Cumner for monitoring the animal colony and Rowan Tweedale for critically reading the manuscript.

\section{Authors' contributions}

J.G and G. $L$ designed the research. G. $L$ and W.K.K performed experiments. J. G, G. L, and W.K.K analyzed the data and wrote the paper. All authors read and approved the final manuscript.

\section{Funding}

We acknowledge support by the Estate of Dr. Clem Jones AO, the National Health and Medical Research Council of Australia [GNT1145580], and the State Government of Queensland (DSITI, Department of Science, Information Technology and Innovation) to J.G. G.L. is supported by a grant from Metal Manufacturers Ltd.

\section{Availability of data and materials}

The authors will make data available upon reasonable request.

\section{Declarations}

\section{Ethics approval and consent to participate}

All animal experimentation was approved by the Animal Ethics Committee of the University of Queensland (approval number QBI/554/17).

\section{Consent for publication}

Not applicable.

\section{Competing interests}

No competing interests exist.

Received: 5 January 2021 Accepted: 15 March 2021

Published online: 09 April 2021

\section{References}

1. Long JM, Holtzman DM. Alzheimer disease: an update on pathobiology and treatment strategies. Cell. 2019;179(2):312-39. https://doi.org/10.1016/j.cell.2 019.09.001.

2. Polanco JC, Li C, Bodea LG, Martinez-Marmol R, Meunier FA, Götz J. Amyloid-beta and tau complexity - towards improved biomarkers and targeted therapies. Nat Rev Neurol. 2018;14(1):22-39. https://doi.org/10.103 8/nrneurol.2017.162.
3. Cummings J, Lee G, Ritter A, Sabbagh M, Zhong K. Alzheimer's disease drug development pipeline: 2019. Alzheimers Dement (N Y). 2019;5(1):272-93. https://doi.org/10.1016/j.trci.2019.05.008.

4. Arndt JW, Qian F, Smith BA, Quan C, Kilambi KP, Bush MW, Walz T, Pepinsky RB, Bussière T, Hamann S, Cameron TO, Weinreb PH. Structural and kinetic basis for the selectivity of aducanumab for aggregated forms of amyloidbeta. Sci Rep. 2018;8(1):6412. https://doi.org/10.1038/s41598-018-24501-0.

5. Sevigny J, Chiao P, Bussière T, Weinreb PH, Williams L, Maier M, Dunstan R, Salloway S, Chen T, Ling Y, O'Gorman J, Qian F, Arastu M, Li M, Chollate S, Brennan MS, Quintero-Monzon O, Scannevin RH, Arnold HM, Engber T, Rhodes K, Ferrero J, Hang Y, Mikulskis A, Grimm J, Hock C, Nitsch RM, Sandrock $A$. The antibody aducanumab reduces Abeta plaques in Alzheimer's disease. Nature. 2016;537(7618):50-6. https://doi.org/10.1038/na ture19323.

6. Schneider L. A resurrection of aducanumab for Alzheimer's disease. Lancet Neurol. 2020;19(2):111-2. https://doi.org/10.1016/S1474-4422(19)30480-6.

7. Howard R, Liu KY. Questions EMERGE as Biogen claims aducanumab turnaround. Nat Rev Neurol. 2020;16(2):63-4. https://doi.org/10.1038/s41582019-0295-9.

8. Leinenga G, Langton C, Nisbet R, Götz J. Ultrasound treatment of neurological diseases--current and emerging applications. Nat Rev Neurol. 2016;12(3):161-74. https://doi.org/10.1038/nrneurol.2016.13.

9. Hatch RJ, Leinenga G, Götz J. Scanning ultrasound (SUS) causes no changes to neuronal excitability and prevents age-related reductions in hippocampal CA1 dendritic structure in wild-type mice. PLoS One. 2016;11(10):e0164278. https://doi.org/10.1371/journal.pone.0164278.

10. Pandit R, Leinenga G, Götz J. Repeated ultrasound treatment of tau transgenic mice clears neuronal tau by autophagy and improves behavioral functions. Theranostics. 2019;9(13):3754-67.

11. O'Reilly MA, Jones RM, Barrett E, Schwab A, Head E, Hynynen K. Investigation of the safety of focused ultrasound-induced blood-brain barrier opening in a natural canine model of aging. Theranostics. 2017;7(14): 3573-84. https://doi.org/10.7150/thno.20621.

12. Pelekanos M, Leinenga G, Odabaee M, Odabaee M, Saifzadeh S, Steck R, Götz J. Establishing sheep as an experimental species to validate ultrasound-mediated blood-brain barrier opening for potential therapeutic interventions. Theranostics. 2018;8(9):2583-602. https://doi.org/10.7150/ thno.22852.

13. Yoon K, Lee W, Chen E, Lee JE, Croce P, Cammalleri A, Foley L, Tsao AL, Yoo SS. Localized blood-brain barrier opening in ovine model using imageguided transcranial focused ultrasound. Ultrasound Med Biol. 2019;45(9): 2391-404. https://doi.org/10.1016/j.ultrasmedbio.2019.05.023.

14. McDannold N, Arvanitis CD, Vykhodtseva N, Livingstone MS. Temporary disruption of the blood-brain barrier by use of ultrasound and microbubbles: safety and efficacy evaluation in rhesus macaques. Cancer Res. 2012;72(14):3652-63. https://doi.org/10.1158/0008-5472.CAN-12-0128.

15. Wu SY, Aurup C, Sanchez CS, Grondin J, Zheng W, Kamimura H, Ferrera VP, Konofagou EE. Efficient blood-brain barrier opening in primates with neuronavigation-guided ultrasound and real-time acoustic mapping. Sci Rep. 2018;8(1):7978. https://doi.org/10.1038/s41 598-018-25904-9.

16. Lipsman N, Meng Y, Bethune AJ, Huang Y, Lam B, Masellis M, Herrmann N, Heyn C, Aubert I, Boutet A, Smith GS, Hynynen K, Black SE. Blood-brain barrier opening in Alzheimer's disease using MR-guided focused ultrasound. Nat Commun. 2018;9(1):2336. https://doi.org/10.1038/s41467-018-04529-6.

17. Leinenga G, Götz J. Scanning ultrasound removes amyloid-beta and restores memory in an Alzheimer's disease mouse model. Sci Transl Med. 2015;7(278):278ra33.

18. Leinenga G, Götz J. Safety and efficacy of scanning ultrasound treatment of aged APP23 mice. Front Neurosci. 2018;12:55. https://doi.org/10.3389/fnins.2018.00055.

19. Leinenga G, Koh WK, Götz J. Scanning ultrasound in the absence of bloodbrain barrier opening is not sufficient to clear beta-amyloid plaques in the APP23 mouse model of Alzheimer's disease. Brain Res Bull. 2019;153:8-14. https://doi.org/10.1016/j.brainresbull.2019.08.002.

20. Pandit R, Chen L, Götz J. The blood-brain barrier: physiology and strategies for drug delivery. Adv Drug Deliv Rev. 2020;165-166:1-14. https://doi.org/1 0.1016/j.addr.2019.11.009.

21. Choi JJ, Selert K, Vlachos F, Wong A, Konofagou EE. Noninvasive and localized neuronal delivery using short ultrasonic pulses and microbubbles. Proc Natl Acad Sci U S A. 2011;108(40):16539-44. https://doi.org/10.1073/ pnas. 1105116108. 
22. Nisbet RM, van der Jeugd A, Leinenga G, Evans HT, Janowicz PW, Götz J. Combined effects of scanning ultrasound and a tau-specific single chain antibody in a tau transgenic mouse model. Brain. 2017;140(5):1220-30. https://doi.org/10.1093/brain/awx052.

23. Janowicz PW, Leinenga G, Götz J, Nisbet RM. Ultrasound-mediated bloodbrain barrier opening enhances delivery of therapeutically relevant formats of a tau-specific antibody. Sci Rep. 2019;9(1):9255. https://doi.org/10.1038/ s41598-019-45577-2

24. Jordao JF, et al. Antibodies targeted to the brain with image-guided focused ultrasound reduces amyloid-beta plaque load in the TgCRND8 mouse model of Alzheimer's disease. PLoS One. 2010;5(5):e10549. https:// doi.org/10.1371/journal.pone.0010549.

25. Kelly PH, Bondolfi L, Hunziker D, Schlecht HP, Carver K, Maguire E, Abramowski D, Wiederhold KH, Sturchler-Pierrat C, Jucker M, Bergmann R, Staufenbiel M, Sommer B. Progressive age-related impairment of cognitive behavior in APP23 transgenic mice. Neurobiol Aging. 2003;24(2):365-78. https://doi.org/10.1016/S0197-4580(02)00098-2.

26. Sturchler-Pierrat C, Abramowski D, Duke M, Wiederhold KH, Mistl C, Rothacher S, Ledermann B, Burki K, Frey P, Paganetti PA, Waridel C, Calhoun ME, Jucker M, Probst A, Staufenbiel M, Sommer B. Two amyloid precursor protein transgenic mouse models with Alzheimer disease-like pathology. Proc Natl Acad Sci U S A. 1997;94(24):13287-92. https://doi.org/10.1073/pna S.94.24.13287.

27. Codd LN, Blackmore DG, Vukovic J, Bartlett PF. Exercise reverses learning deficits induced by hippocampal injury by promoting neurogenesis. Sci Rep. 2020;10(1):19269. https://doi.org/10.1038/s41598-020-76176-1.

28. Ittner LM, Ke YD, Delerue F, Bi M, Gladbach A, van Eersel J, Wölfing H, Chieng BC, Christie MDJ, Napier IA, Eckert A, Staufenbiel M, Hardeman E, Götz J. Dendritic function of tau mediates amyloid-beta toxicity in Alzheimer's disease mouse models. Cell. 2010;142(3):387-97. https://doi. org/10.1016/j.cell.2010.06.036.

29. Pirttila T, et al. Soluble amyloid beta-protein in the cerebrospinal fluid from patients with Alzheimer's disease, vascular dementia and controls. J Neurol Sci. 1994;127(1):90-5. https://doi.org/10.1016/0022-510X(94)90140-6.

30. van Praag H, Shubert T, Zhao C, Gage FH. Exercise enhances learning and hippocampal neurogenesis in aged mice. J Neurosci. 2005;25(38):8680-5. https://doi.org/10.1523/JNEUROSCI.1731-05.2005.

31. Lesburgueres $\mathrm{E}$, et al. Active place avoidance is no more stressful than unreinforced exploration of a familiar environment. Hippocampus. 2016 26(12):1481-5. https://doi.org/10.1002/hipo.22666.

32. Kuo YM, Beach TG, Sue LI, Scott S, Layne KJ, Kokjohn TA, Kalback WM, Luehrs DC, Vishnivetskaya TA, Abramowski D, Sturchler-Pierrat C, Staufenbiel M, Weller RO, Roher AE. The evolution of a beta peptide burden in the APP23 transgenic mice: implications for A beta deposition in Alzheimer disease. Mol Med. 2001;7(9):609-18. https://doi.org/10.1007/BF03401867.

33. Poon CT, Shah K, Lin C, Tse R, Kim KK, Mooney S, Aubert I, Stefanovic B, Hynynen K. Time course of focused ultrasound effects on beta-amyloid plaque pathology in the TgCRND8 mouse model of Alzheimer's disease. Sci Rep. 2018;8(1):14061. https://doi.org/10.1038/s41598-018-32250-3.

34. Hsu PH, Lin YT, Chung YH, Lin KJ, Yang LY, Yen TC, Liu HL. Focused ultrasound-induced blood-brain barrier opening enhances GSK-3 inhibitor delivery for amyloid-beta plaque reduction. Sci Rep. 2018;8(1):12882. https:// doi.org/10.1038/s41598-018-31071-8.

35. Karakatsani ME, Kugelman T, Ji R, Murillo M, Wang S, Niimi Y, Small SA, Duff KE, Konofagou EE. Unilateral focused ultrasound-induced blood-brain barrier opening reduces phosphorylated tau from the rTg4510 mouse model. Theranostics. 2019;9(18):5396-411. https://doi.org/10.7150/thno.28717.

36. Xhima K, et al. Focused ultrasound delivery of a selective TrkA agonist rescues cholinergic function in a mouse model of Alzheimer's disease. Sci Adv. 2020;6(4):eaax6646.

37. Kastanenka KV, Bussiere T, Shakerdge N, Qian F, Weinreb PH, Rhodes K, Bacskai BJ. Immunotherapy with aducanumab restores calcium homeostasis in Tg2576 mice. J Neurosci. 2016;36(50):12549-58. https://doi.org/10.1523/ JNEUROSCI.2080-16.2016.

38. D'Haese PF, et al. Beta-amyloid plaque reduction in the hippocampus after focused ultrasound-induced blood-brain barrier opening in Alzheimer's disease. Front Hum Neurosci. 2020;14:593672. https://doi.org/10.3389/ fnhum.2020.593672.

39. Asquier $\mathrm{N}$, et al. Blood-brain barrier disruption in humans using an implantable ultrasound device: quantification with MR images and correlation with local acoustic pressure. J Neurosurg. 2019;132(3):875-83. https://doi.org/10.3171/2018.9.JNS182001.

40. Meng Y, Pople CB, Lea-Banks H, Abrahao A, Davidson B, Suppiah S, Vecchio LM, Samuel N, Mahmud F, Hynynen K, Hamani C, Lipsman N. Safety and efficacy of focused ultrasound induced blood-brain barrier opening, an integrative review of animal and human studies. J Control Release. 2019; 309:25-36. https://doi.org/10.1016/j.jconrel.2019.07.023.

41. Eede P, Obst J, Benke E, Yvon-Durocher G, Richard BC, Gimber N, Schmoranzer J, Böddrich A, Wanker EE, Prokop S, Heppner FL. Interleukin12/23 deficiency differentially affects pathology in male and female Alzheimer's disease-like mice. EMBO Rep. 2020;21(3):e48530. https://doi. org/10.15252/embr.201948530.

\section{Publisher's Note}

Springer Nature remains neutral with regard to jurisdictional claims in published maps and institutional affiliations.
Ready to submit your research? Choose BMC and benefit from:

- fast, convenient online submission

- thorough peer review by experienced researchers in your field

- rapid publication on acceptance

- support for research data, including large and complex data types

- gold Open Access which fosters wider collaboration and increased citations

- maximum visibility for your research: over $100 \mathrm{M}$ website views per year

At BMC, research is always in progress.

Learn more biomedcentral.com/submissions 